\title{
Safer Schools in an Age of Mass Violence: Back to the Basics of Public Health
}

\author{
Irwin Redlener, MD, Andrew L. Garrett, MD, MPH, and Gregory A. Thomas, MS
}

$\mathrm{S}$ chools in the US are by and large safe environments where millions of our children are secure and thrive. Outbreaks of fatal violence like the recent shootings at Virginia Polytechnic Institute and State University (Virginia Tech) are, fortunately, rare. In fact, the odds of a student losing his or her life to homicide are 50 times more likely while off school grounds. Because of the extraordinary consequences and societal shock waves caused by a low-probability mass casualty disaster in a school, this becomes one of the "all hazards" that campuses must plan to face, albeit with limited budgets and resources.

Events of this kind are inevitably - and understandablyfollowed by analyses, investigations, and hearings examining what went wrong and what can be done to avert such catastrophes in the future. Too often, however, we fall into the pattern of "planning for the last disaster," forgetting that a solid foundation of purposeful preparedness for a variety of emergency or disaster scenarios will likely serve the greatest good for the students, faculty, and staff who will face the next unknown crisis in a school or on a campus.

This is not to say that we should bypass the opportunity to learn from the lessons and unpredicted shortfalls that any crisis reveals. Within weeks of the lethal violence at Virginia Tech, the first round of meetings to analyze the catastrophe was organized in Washington, DC. Officials from the Departments of Justice, Education, and Health and Human Services, along with a range of key stakeholders, participated in the discussions that focused on conditions or gaps that may have contributed to or exacerbated the consequences of this particular incident. The result of this after-incident analysis was a series of specific actions that could reduce the risk for a similar occurrence.

This is not the first time such discussions have taken place in the aftermath of a particularly devastating school shooting, however. For instance, the detailed report of the US Secret Service's Safe Schools Initiative, prepared after the 1999 Columbine High School shootings, contains comprehensive, even groundbreaking, insights gleaned from thorough analyses of this and prior notorious school shootings. Unfortunately, until now the evidence-driven conclusions and recommendations of this 2002 report had gone largely unnoticed. In fact, the US General Accounting Office's May 2007 report, Status of [Public] School Districts' Planning and
Preparedness, highlights the continuing shortfalls in the capacity of schools and campuses to protect and optimally care for children and youth during and after a major disaster. It seems that each new incident is referred to as a "wake-up call," and hopefully prompts new policies and resources to prevent or mitigate similar occurrences in the future. Actual follow-up is recurrently dismal, however, and reactions to the event turn out to be more like pressing the snooze button on an alarm clock.

One factor that undoubtedly reduces the likelihood of following new policies recommended in the aftermath of every tragedy is that such incidents are actually highly uncommon, clearly fitting into the classic category of "low probability, high consequence" disasters. As is the case with disaster planners in general, for campus officials it is always a challenge to prioritize the application of limited resources to events that are legitimately rare. Consciously or not, a decision is often made to direct available resources to hazards that are deemed more likely to occur.

That said, there are other scenarios-in addition to that of the lone, mentally ill campus shooter-that would be classified as highly unlikely, although not out of the question. Such is the case for the possibility of specific targeting of a campus by organized terrorists. School sites and facilities are known as "soft targets," vulnerable to devastating attacks because access is relatively simple, absolute security virtually impossible, and the potential for terrorinduced, high degrees of society-wide grief and reaction are ensured. Sadly, such a possibility cannot be ruled out, as is suggested by events and discoveries over the past few years including the following:

- In late 2001 a planned attack on a US school in Singapore was thwarted by counterterrorism officials.

- More than 150 children were slain in a school in Beslan, Russia, in 2004 before the perpetrators could be neutralized by authorities. (The concern is, of course, that a Beslan-style attack on a US school or campus cannot be dismissed as a potential future threat and that we are poorly positioned to respond to the specific needs of children in a mass casualty incident.)

- In 2004 an Iraqi insurgent captured in Baghdad was found to have had detailed plans and layouts of 8 school districts across 6 US states. 
- The emergence of attacks on schools as a more mainstream tool of warfare and terrorism: the intentional targeting of a primary school in Afghanistan in 2006 and an explosives attack on a group of 20 children playing soccer as well as a suicide bomb attack at a college in Baghdad, both in February 2007. In March 200732 children and teachers were taken hostage in Manila by armed gunmen.

- Writings by al Qaeda leaders have spoken to the mandate to attack US citizens in general and children in particular. Sulieman Abu Gheith, a close associate of al Qaeda leader Osama Bin Laden, reportedly stated, "We have not reached parity with [the Americans]. We have the right to kill 4 million Americans, 2 million of them children."

Perhaps the point is that the United States cannot afford to be sanguine about the potential dangers facing our children and young people, even if the risk seems low. The risk for occurrence must be balanced by considering the potential for extreme, widespread, and crippling repercussions of such an event occurring without adequate preparedness in place.

Just as with any other community facing potential hazards, the goals of reducing campus violence and increasing resiliency with respect to isolated shootings or terrorism should include strategies that are focused on prevention, mitigation, and response. Prevention, the sine qua non of public health practice, should be the first priority in thinking about securing the safety of schools and campuses. This exists across 2 realms: preventing the hazard itself from occurring and taking steps to decrease the vulnerability of those affected by a hazard. Balancing individual privacy and an open academic environment versus the need to share medical and mental health information for the good of the student and the community will be a challenging step in the current climate, as will be the issue of address- ing the loopholes that allowed Cho Seung-Hui to acquire the weapons he used for the murders at Virginia Tech. With the proper judicial procedures in place, however, educational institutions could have a far greater ability to report, manage, and control students who may pose grave danger to themselves or others.

The mitigation of disaster hazards is another set of challenges that includes the consideration of greatly enhanced capacity to rapidly communicate warnings and emergency instructions on a campus or in a school facility; much more consistent and comprehensive disaster planning with local, noncampus response agencies; and awareness training for students, faculty, and staff.

The federal inquiry into the Virginia Tech tragedy highlighted many of the next steps that may serve to increase the safety of students, faculty, and staff in the face of life-threatening violence on campus. In fact, these recommendations may prove to be extremely useful. By applying the principles of good public health and response practices, we may reasonably hope to reduce the incidence of campus shootings and mitigate the consequences of those events we cannot predict or prevent.

\section{About the Authors}

Irwin Redlener is Director of the National Center for Disaster Preparedness, Andrew L. Garrett is Director of Planning and Response, and Gregory A. Thomas is Deputy Director of Planning and Response, National Center for Disaster Preparedness, Columbia University Mailman School of Public Health.

Correspondence and reprint requests to Dr Irwin Redlener, 722 W 168th St, Suite 1014, New York NY 10032 (e-mail: ir2110@columbia.edu).

Received and accepted for publication July 3, 2007.

ISSN: 1935-7893 (C) 2007 by the American Medical Association and Lippincott Williams \& Wilkins.

DOI: 10.1097/DMP.0b013e31814b8bcd 